\title{
Disclosing the Tourism Dynamic Packages
}

\author{
Luís Ferreira ${ }^{1,3}$, Goran D. Putnik ${ }^{2,3}$, Maria Manuela Cruz-Cunha ${ }^{1,3}$ \\ ${ }^{1}$ Polytechnic Institute of Cávado e Ave, School of Technology, Lugar do Aldão \\ 4750-810 Vila Frescainha S. Martinho - Barcelos, Portugal \\ ${ }^{2}$ University of Minho, School of Engineering, Campus de Azurém, 4800-158 Guimarães, \\ Portugal \\ ${ }^{3}$ CITEPE Research Centre, University of Minho, Campus de Azurém, \\ 4800-158 Guimarães, Portugal \\ lufer@ipca.pt,putnikgd@dps.uminho.pt; mcunha@ipca.pt
}

\begin{abstract}
This paper describes the Open Tourism Initiative (OTI), exploring its application in tourism, based on the Virtual Enterprise (VE) organizational model. It assumes as essential to assure the permanent alignment between a tourism solution and the client's interests and expectations, which claims for a reliable integration and dynamic networking of the entities providing that solution (the VE). When a member of the VE scheduled to provide a given service is somehow conditioned, unable to participate or has to be disentailed from the network, or due to events not necessarily measurable or deterministic, it is necessary to reconfigure the VE in almost real time. OTI handles dynamic tourism packages under reconfigurable VE environment.
\end{abstract}

Keywords: meta-information, systems integration, business models, tourism, Web services, interoperability, ontology, Web Processing Service, Virtual Enterprises, Market of Resources.

\section{Introduction}

With the advent and acceptance of a new technology, new services and new challenges emerge naturally. The ubiquity of the Web is clear, and determines the necessary and fast adaptation of processes that took much time to be implemented and assimilated. The emerging need (and ability) to systematically integrate technologies with processes, in order to efficiently and effectively align information variants with its inherent search is certainly a major challenge for computing sciences. In actual economic activities, client-supplier frontier vanished. E-Business, e-Commerce, etc., transformed business and commerce processes, making them less self and unique, less "ours" and more global [1].

The scientific community is concerned with the exploitation of the potential of technologies both for the individual and for the society, democratizing the access, leveling the access differences and maximizing the respect and preservation of people rights and values. This way, Web technologies enable also a new form of tourism (either of leisure, science, culture or traditions), supported by more and more complex networks of participants. We are facing the need of virtualization of tourism services. 
How shall we see this new socio-technological framework/environment in such an activity, each time more global and timeless, but always intended very personal?

Each client request has its own characteristics and requires an individualized answer. Obviously the ability to close the gap between the client desire and the suitable solution (i.e. tourism solution) cannot be accomplished by a single entity (enterprise or organization). There is no enterprise owning a so complete domain of resources that allow a competitive and global solution to the market demand. Instead, a solution is the result of the integration of a set of service providers that under the format of a Networked and Virtual Enterprise is able to a better alignment to the market opportunities, i.e., the satisfaction of the specific needs of an end-user. Simultaneously, this network of providers keeps a self dynamic to keep a permanent alignment.

The paper proposes a semantic architecture, able to support the integration and processing of information and/or of processes, disperse and global, of every sort of information that can be (or will be) directly or indirectly related to tourism activities. It describes the structure of Tourism Objects (TO) through specific meta-information and presents brokerage mechanisms able to browse and find interrelations, most of them marked by the temporality of useful and/or available information. It is intended that this approach be globally recognized, to make it an open initiative, which could easily be used by any actor, able to support tourism activities everywhere and of every kind, based on the importance of finding ways to structure (unstructured) information universally, which could be processed by computers. Mechanisms for indexing and discovery are also presented.

The remainder of this paper provides a background for the main technologies and integration initiatives around tourism e-business on section 2. Section 3 presents the Open Tourism Initiative and its architecture and main technical components. Section 4 concludes the paper and gives some suggestions for future work.

\section{Integration Initiatives}

This section introduces some background information on state-of-the-art developments and technologies able to support the proposed solution.

\subsection{Open Tourism Consortium}

The Open Tourism Consortium - OTC ${ }^{1}$, is a standby consortium of companies, government agencies, individuals, and universities participating in the open development of publicly available standards and software applications to support tourism activities. Their major goals were to develop a XML based data exchange language for objects and events of interest to tourists (TourML) and an open source parser for this language, able to insert the data into a relational database based on the standard data model. It focuses the capacity to describe touristic information since it could be available in multiple devices. Besides the fact that this initiative promotes u-

${ }^{1}$ http://www.opentourism.org; http://www.terry.uga.edu/ rwatson/otc/ 
Commerce and being already supported by a XML Schema, it disables or makes difficult the necessary automatic and agile reconfiguration of a tourism service [2].

\subsection{Dynamic Tourist Packages}

Although recent, the concept of Dynamic Packaging is already embedded in several areas, and the tourism is one that gives important visibility to the concept. However, current more evident developments manifested on the web, are nothing but search tools that offer the tourist some autonomy in defining his vacation schedule.

Jorge Cardoso [3] describes the role of the Semantic Web as support for a typical mode of eTourism, which relates a set of processes and ideas to support the integration of tourism information coming from multiple sources. The ANOTA project already explored the Semantic Web for improving dynamic tourist packages commercialization, using domain ontology to annotate information sources on tourism services [4]. The proposed service allows to aggregate information from multiple sources (including websites) according to the preferences of tourists, with the availability of resources and services for the travel dates. However, how the demand of information between repositories is made, and how the system reacts to changes in plans for the tourist or the unavailability of the resources and suppliers (reconfiguration), is not described by the authors.

\subsection{Ontologies on the era of Service Oriented Architecture}

In the beginning, the Remote Procedure Calling (RPC) supported the first needs to establish the "communication" among complex and heavy systems (mainly computers). From there to nowadays, technical handicaps forced new applications, which in turn allowed new technologies and new features. Today's applications are seen as services, because in the meanwhile, the Internet and its new capacities appeared. So, the actual challenge demands the "communication" (that is to say, the integration) among these services.

So, if we have a lot of services, the question now is, how to get the best one? How to classify and compare services? Once again a handicap: the need to select one in a set of possibilities. The ontologies show up again as an important tool to get some formal semantic (meta-information) description for existent services, allowing their interoperability. Web Services Modeling Ontologies [5] or Semantic Annotation for WSDL and XML Schema [6] are two relevant researching initiatives on this.

In another perspective, with Service Oriented Architecture (SOA) acceptance, appeared new (web) commerce models, new team organization and necessarily new support applications; but this emerging context happens mainly inside the company. Among companies, the goal focuses the integration of different SOA implementations [7]. The actual web services technological support, as they are specified, could not support new business process automation emergent demands, like authentication, security, persistence, transaction and others. Considering that, and because the web should continue to be the "rail", the common (a)synchronous web services should be 
extended to have this under consideration. These were kernel arguments for Web Service Enhancements (WSE) [8].

Considering the possibility to have multiple and continuous contextual invariants changing, SOA needs to be prepared to react to, if possible, to be reconfigurable, according to received events. It should behave like an event driven architecture, or, as suggested for ontologies [6], a context-aware architecture, following publish/subscribe or even broadcast models (demand variations can change business process); loosely coupled units production (each unit knows nothing about others) must be composed and scheduled under governance mechanisms, ensuring service satisfaction. We cannot ignore that events are not all predictable [9].

Considering a touristic activity described with common XML/DTD (Figure 1) it is easy to see that it should be needed much more data to allow the description of previous mentioned new requirements. The less accepted XML Schemas could (or should) now perform a significant role on this technologic demand. Mapping XML to Semantic data should be the goal [6]!

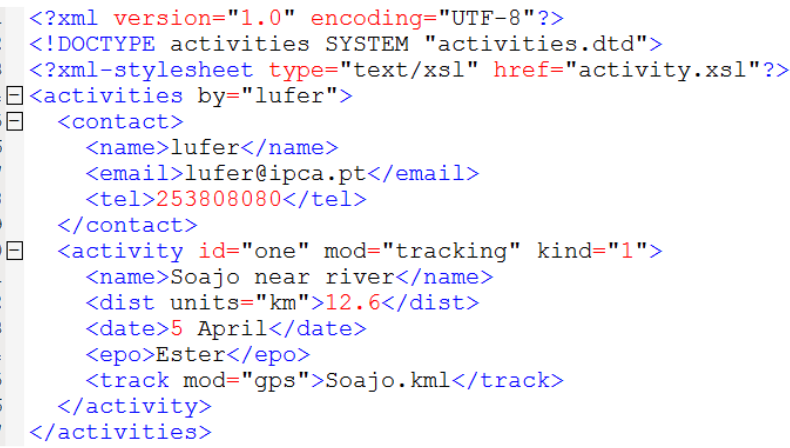

Fig. 1. Touristic activity XML description

\subsection{Tourism Services in the Web}

It is evident the growth of world tourism market and the inherent governmental concerns on tourism. If the previous marketing tourism strategies bet on 8P's Morrison's elements (price, product, place, promotion, people, partnership, package and programming) [10], the next success key could be the inclusion of another $\mathrm{P}$ (personalized, or customized). The tourist profile evolved, having a lot of distinct opportunities, his needs or interests continuously change and, having a handheld device (ex. mobile phone) with him, he can and he wants to get easily in touch with the world [11]. So, what the tourism needs now is to pick up tourist interest, and no more stay waiting for the tourists' choices. Consequently the tourist wants to try to enjoy the new possibilities of the available (multi) media infra-structure, the internet [12]. Despite of this, the tourist has a complex task to do whenever he needs to plan its touristic activity.

It is not easy to find the correct, wanted or needed information according to his interests. The actual web search services (like Google, Yahoo, etc.) are generalist (so not specialized) and can go through information using almost nothing but boolean 
calculus. E-marketplaces did a relevant effort to specialize the offer but only focused on electronic exchanges ${ }^{2}$. Knowing this, Google and New York Government jointed on nycgo ${ }^{3}$ web site, working as a Tourism Data Center, where, under Travelocity service, the tourist with his profile, should plan his accommodation, plains and cars. Using interactive tables (using touch screen technology) with Google applications (Maps, Earth, etc.), the tourist can define desired routes and print the resulting map with desired points to visit [13].

Tourism is clearly an activity which claims for this world of services virtualization. A travel agent will be satisfied if he can offer services packages geographically distributed. Analyzing historical quality of services, the tourism agent should have predictable and guaranteed quality of the desired service. Hence, he needs no more sub-contract many enterprises or to visit several places to make sure that everything is properly planned. Everything should be integrated.

Under the client satisfaction perspective, between service discovery and its applied evaluation, there is usually an important gap (time, area, etc.). There is (almost) no warranty that the offered service will be the best one. But it is very important to certify this, previously offering some kind of service evaluation and certification. There must be some pre-process or agent which allows the services ranking for particular context. This could be achieving using, for instance, Web Processing Service $e^{4}$ logic.

\subsection{Information Retrieval and Searching Strategies}

The (almost considered traditional) e-Commerce is now changing directly to mobile commerce (m-Commerce) over the Internet. This already consolidated information channel is essential for nowadays tourism business activity and promotes new emergent (and necessary) tourism marketing strategies [14]. The possibility to get useful information depends on the capacity to retrieve, search and interpret it. Considering this and accepting tourist information ubiquity, the actual mobile tourist profile looks real and mobile devices should be the key tool for information retrieval.

Looking for relevant mobile tourism and travel research initiatives, temporality, user preference and geographical information are three main essential supported concepts. Personalized online tourism services [15] are wellcome services, for instance, under electronic tourist guides; preference-based searching mechanisms align better searching results with tourist interests [16], multiagent Knowledge-Based Recommender deal well with disperse information and improve the consistency of recommended results [17]; Modularized ontologies models well contextual information, allowing better semantic matching between tourism service and user context [18].

It is worldwide accepted that doing data mining over large multidimensional (touristic) information, inherent of global (tourism) commerce activity, is very complex and problematic. Although repositories are supported by increased powerful databases, dynamic queries or another refined searching mechanism, are not enough to grant an efficient result. Being tourism a very complex and scattered commercial

\footnotetext{
2 http://www.e-businessguide.gov.au/improving/e-marketplaces

${ }^{3}$ http://nycgo.com/

${ }^{4}$ http://www.opengeospatial.org/standards/wps
} 
area, it results difficult to get their accepted services global formal description (under ontologies, RDF, etc.) able to ensure their interoperability.

\subsection{The Clouding "wave"}

The next big trend sounds nebulous, but it's not so fuzzy when you view the value proposition from the perspective of IT professionals!

Eric Knorr, Galen Gruman | InfoWorld, 2010

Today the cloud is the most familiar "cliché" in almost new emergent paradigms, decisions or strategies realignment. Once associated with computer processing, the idea is to increase the capacity or add capabilities on the fly, without investing in new infrastructure, training new personnel, or licensing new software ${ }^{5}$. The actual offer is based on SaaS (Software as a Service) model with no aggregators or integrators. Being member of the cloud means nothing more than to belong to a tremendous scattered potential capacity "infrastructure". The acceptance of this new paradigm is already evident in virtual enterprise constitution ${ }^{6}$ and virtual development ${ }^{7}$. SOA and Web Services are seen as the technological base for clouding support once it adopts their application and physical infrastructures ${ }^{8}$. There are already Service Commerce Platforms (a hybrid of SaaS and MSP-Managed Service Providers) that coordinate the service delivery and pricing within the specifications set by the user.

So, clouding is real $^{9}$ and in terms of tourism, the clouding is not an abstraction! There are already several (isolated) touristic services on the cloud, in pay as you go style, but still lack tools to its integration and orchestration ${ }^{8}$. So, applying cloud potential on offering agile and virtual tourism services is still an ideal. But the logic under technological support to deal with available (distributed) servers on cloud net ${ }^{10}$ should be considered on supporting technology for virtual tourism services providers' selection, their composition and governance.

“... as virtualization and SOA permeate the enterprise, the idea of loosely coupled services running on an agile, scalable infrastructure should eventually make every enterprise a node in the cloud." 5

\section{OPEN TOURISM INITIATIVE}

This section explores the Open Tourism Initiative (OTI), an architecture proposed to handle dynamic tourism packages under Virtual Enterprises organizational model, viewed as a model with a high reconfiguration dynamics of the inter-organizational structure.

\footnotetext{
${ }^{5} \mathrm{http}$ ///www.infoworld.com/d/cloud-computing/what-cloud-computing-really-means-031

${ }^{6} \mathrm{http}: / /$ technology-global.com/increases-cloud-computing-virtual-enterprise-17/

${ }^{7}$ http://www.flightglobal.com/articles/2010/04/27/340790/cloud-computing-to-enable-virtualdevelopment.html

${ }^{8}$ http://www.ibm.com/developerworks/websphere/techjournal/0904_amrhein/0904_amrhein.html

${ }^{9} \mathrm{http}: / / \mathrm{www}$.eyeofdubai.com/v1/news/newsdetail-42399.htm

${ }^{10}$ www.vmware.com/solutions/cloud-computing
} 


\subsection{Usage Scenario and Use Case}

Considering an use case a sequence of interactions between a service requestor and one or more services, which achieve measurable results for the requestor, and usage scenario an atomic step in a path through an use case [19], we imagine a touristic activity where tourist go through multiples (virtual) services (scenarios) in a search for achieving its demands (use case).

The Open Tourism Initiative proposed by the authors in [20] works like a support layer to grant inter-operability between tourism services providers, organized under the format of a virtual enterprise and the support to its subsequent reconfigurations, traduced by the several instances the virtual enterprise suffers along its life-cycle.

The structured definition of Tourism Objects (TO) is the base for the OTI supporting architecture. All the information that can be imagined to be associated with a TO, should be represented in a semantic model or ontology. The overall OTI architecture (Fig. 2) has as main parts: the source of information or Tourism Service Providers (TSP) (future Open Tourism Provider), the Tourism Object Repository (TOR) which archives and manages tourism objects, behaving like a Market of (Tourism) Resources, and Tourism Object Broker (TOB), which bridges the gap between the tourist and all the information he seeks.

Regardless time or context, all TO (coming from business entities, individuals, web, etc.) must be automatically or manually (explicitly) registered (Fig. 2, step1) and correctly classified or "cataloged" in TOR, using a specific domain ontology metainformation (Open Tourism Ontology - OTO) (Fig. 3).

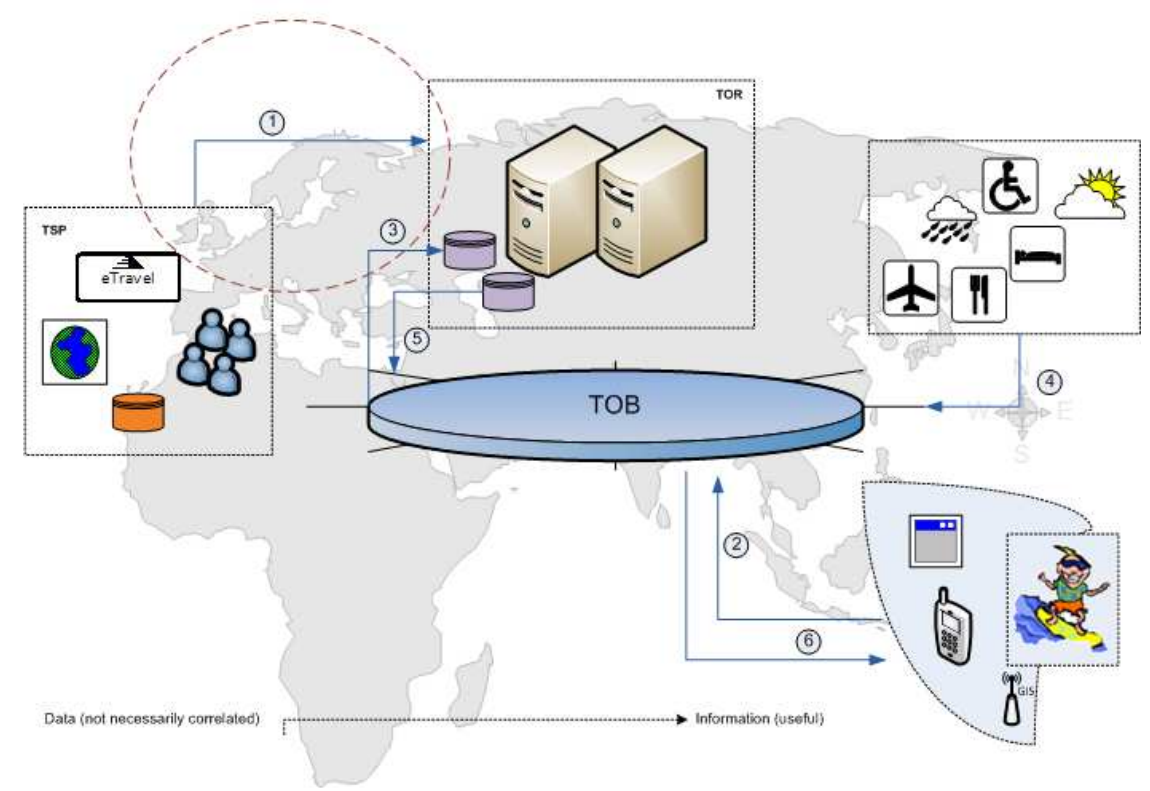

Fig. 2. OTI Architecture 
In a traditional behavior, the broker (TOB) analyzes the tourist demand (step 2), gets known tourism information (step 3), considers existing relevant constraints (derived from weather, travel, accommodation, etc ...) (step 4), in order to get a result (step 5), and prepare the "answer" or "solution" (step 6) to the tourist. However, this "receipt" does not show the dynamic nature of this process, where all processes should not necessarily happen in a sequential way. The system should respect to real-time available information and set/configure (reset/reconfigure) other possible solutions. In essence, the system should never respond with a "no" but with a set of answers that satisfy more or less the expected interests. Responses should be submitted in compliance with that ranking ${ }^{11}$ respecting those criteria initially defined by the tourist.

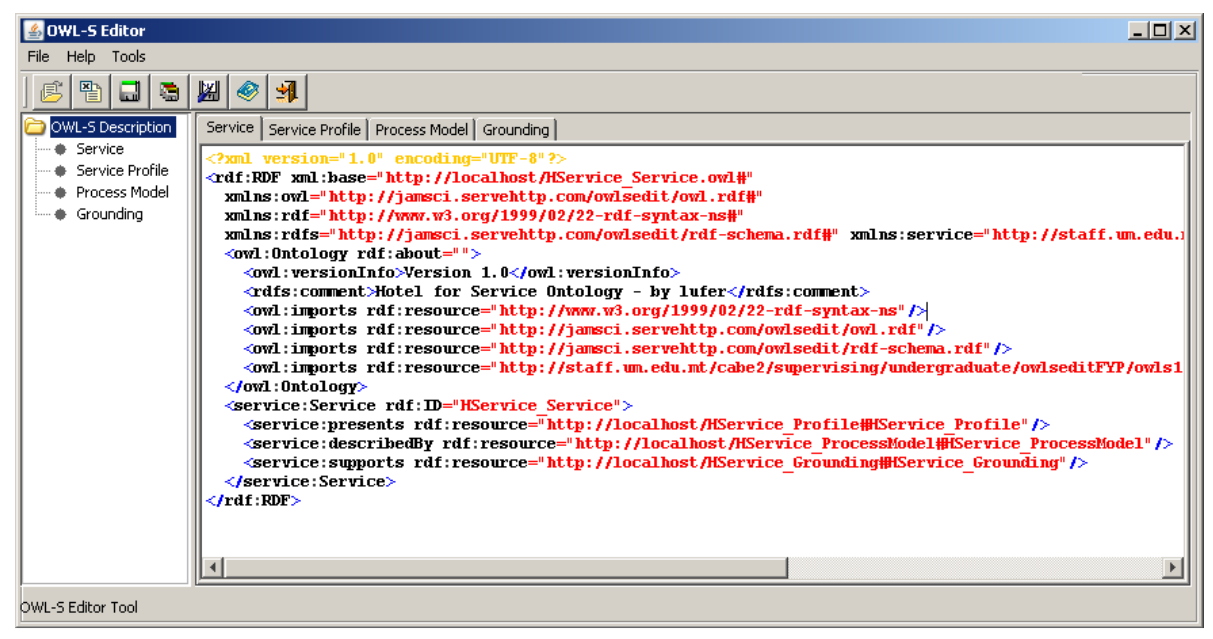

Fig. 3. OTO Touristic Service description

\subsection{Service Reconfiguration}

Although each registered TO has its necessary describing (meta) information, many other kind of information should be needed and its existence should influence the service satisfaction.

For a tourist, the main interest is the quality of service, discarding details of how it should be supported. For him there must be only one entity providing the solution or the tourism service (for instance, a travel agency) but its implementation necessarily involves several distinct but integrated entities, each providing its part of the solution (air plane, accommodation, catering, etc.).

But what happens if something goes against planned? An air-plane loosed, an activity suspend because the weather conditions, etc.?

Face to unexpected situations, the system of providers must be "reconfigured" to avoid defrauding the tourist expectative, i.e., to assure the permanent alignment between o tourist and the tourism solution.

${ }^{11}$ Under fuzzy criteria? 
Support decision, backtracking or rollback mechanisms should be used and sometimes the tourist (or its agent) should need to moderate the process. From the technical point of view, reconfiguration requires the adequate integration of information systems (IS) of the universe of potential providers of TPS. The process relies on a properly integrated IS architecture, robust but not rigid.

\subsection{TO Broker}

In our model, the broker (TOB) works firstly as a knowledge resource driving the definition of the end-user tourism project, and designing the system of tourism objects and service providers that "best fit" his requirements or expectations. This conduces to the creation of the VE aligned with the tourism project. The broker is also a reconfiguration manager, as the permanent alignment requires the VE to be aligned with the tourism project. As we could see above, reconfiguration appears due to several causes: performance of the involved providers, change in the end-user requirements (and hence in the tourism project), or to external/ uncontrolled causes.

As happened with WSDL/UDDI Web services support [21], the broker will "navigate" in multiple tourism objects, trying to match those which satisfy particular criteria. It must filter (well) structured data (RDF/ATOM/XML/JSON etc.) and must be able to compose several (web tourism) services.

Its behavior should be supported by (a)synchronous web services, respecting critical services (time or transaction dependents). They should be "helped" by Web Processing Services (WPS), trying to offer autonomous processing and scheduling capacity [22]. A cloud computing should be useful here once should accelerate the need data mining process over a Market of Tourism Resources (TOR).

\subsection{OT Ontology}

As previously mentioned, the OTI should be supported by domain ontology (OTO), which should completely describe each tourism object. Once tourism covers multiple areas, this ontology should be able to learn [23] from multiple and heterogeneous data source formats (even other ontologies), services classification and quality, etc., allowing its enrichment with new concepts and relations [18].

Having this meta-information, tourism objects should be interoperable, and using syndicance mechanisms (seeds, atoms, etc.) or even specific search engines, this (meta) information should be available for other systems.

The expected capacity to learn will require its interaction with existent ontologies, like Open Travel Alliance (OTA), Geography Markup Language (GML), and others [24].

\section{Conclusions and Future works}

e-Commerce and e-Business forced enterprises to undertake important transformations and reorganizations (intra and inter). This occurred with the web and will be repeated 
in the Cloud (as Google CEO Eric Schmidt once said, better thinking now on WWC World Wide Computer, that is, what is behind u-Commerce, ubiquity).

The Tourism is a particular case which shows clearly this reconfiguration and demonstrates the impacts of internet acceptance. There are a lot of sites which offer multiple services, from simple information to complete activity planning, including accommodation reservation and travel.

However not yet everything looks easy indeed. It is very difficult to have several (unknown and distinct) entities working together where the global planning conditions has been changed, for any reason.

The globalization (of information and offer), allows tourists to change constantly their plans. It should be need the services reconfiguration and necessarily deal with their impact on supporting systems and related information.

The Open Tourism Initiative here proposed and explored, tries to handle with this tourism service dynamic reconfiguration using a particular IT architecture. The services are provided by Tourism Virtual Enterprises which need to quickly adapt and reconfigure to be aligned with expected touristic service. Each touristic service provider can interact, with rigor and opportunity, using any informatics platform.

So, after the tourism object description and registration via one domain ontology, there should be a brokering mechanism which will support their discovery and orchestration process. It should be possible also to offer a decision support system to orient tourist in its plan redefinition.

Considering this, the future OTI architecture should deal with a specific domain ontology (OTO - Open Tourism Ontology) to describe Open Tourism Objects (OTO), concerning temporality, accessibility, etc. and a Tourism Object Chain (TOC) which will support scheduling and composition to grant OT inter-operability.

But having such architecture should be enough to support emergent needs?

\section{References}

1. Berners-Lee: The Web Of Things. ECRIM New 72 (2008)

2. Monod, E.: Open Tourism: Cultural heritage tourism enhanced by open technologies and ucommerce. European Comission - FP6 The Sixth Framework Programme RTD (2004)

3. Cardoso, J.: E-Tourism: Creating Dynamic Packages using Semantic Web Processes. W3C Workshop on Framework for Semantics in Web Services (2005)

4. Murua, I., Lladó, E., Llodrá, B.: The Semantic Web for Improving Dynamic Tourist Packages Commercialisation. Fundación IBIT, ROBOTIKER, Madrid (2005)

5. Bruijn, J., Fensel, D., Keller, U.: Using the Web Service Modelling Ontology to enable Semantic eBusiness. Communications of the ACM. ACM (2005)

6. Kopecký, J.: SAWSDL - Status and relation to WSMO. WSMO teleconference. Universität Innsbruck (2007)

7. Sprott, D., Wilkes, L.: Understanding Service-Oriented Architecture. The Arquitecture Journal. Microsoft (2004)

8. Erl, T.: Service-Oriented Architecture; A field guide to integrate XML and Web Services. Prentice Hall, Alexandria (2007)

9. Hoof, J.: EDA extends SOA and why it is important. SOA and EDA : Thoughts on Service Oriented Architecture and Event-Driven Architecture (2006) 
10. Ma, Y.-T., Crestan, A.: Taiwan's challenges for Significant International Tourism Market Growth. The Proceedings of the10th International Digital Government Research Conference (2009)

11. GS1: Mobile Commerce: opportunities and challenges. A GS1 Mobile Com White Paper. GS1 (2008)

12. Nielsen, L.B.: Post Disney experience paradigm? Southern University of Denmark (2004)

13. Hudge: The City of New York Teams Up with HUGE to Launch NYCGo.com. (2009)

14. Liu, S.-q.: A Theoretic Discussion of Tourism E-commerce. Chongqing Technology and Business University (2005)

15. Kenteris, M., Gavalas, D., Economou, D.: An innovative mobile electronic touris guide application. Springer-Verlag, London (2007)

16. Hill, R., Wesson, J.: Using Mobile Preference-Based Seraching to Improve Tourist decision Support. SAICSIT 2008. ACM (2008)

17. Lorenzi, F.: A Multiagent Knowledge-Based Recommender Approach with Truth Maintenance. RecSys'07. ACM (2007)

18. Barta, R., Feilmayr, C., Grun, C.: Covering the Semantic Space of Tourism - An Approach based on Modularized Ontologies. 1st Workshop on Context, Information and Ontologies. ACM, Heraklion, Greece (2009)

19. Zaremba, M.: Web Services Architecture Usage Scenarios - Selected Use Cases \& Usage Scenarios. W3C Working Group (2004)

20. Ferreira, L., Putnik, G.D.: Open Tourism Initiative. Teknee (2008)

21. Endrei, M.: Patterns: Service-Oriented Architecture and Web Services. RedBooks IBM (2004)

22. Web Processing Services. OCG - Open Geospatial Consortium (2005)

23. OLP2, P.: Bridging the Gap between Text and Knowledge. OLP2 - 2nd WorkShop on Ontology Learning and Population. Coling/ACL, Sidney-Australia (2006)

24. Maedche, A.: Ontology Learning for the Semantic Web. The Kluwer International Series in Engineering and Computer Science. Springer (2002) Volue 655

25. Sabou, M., Wroe, C., Goble, C., Stuckenschmidt, H.: Learning Domain Ontologies for Semantic Web Service Descriptions. Elsevier Science (2005) 